\title{
Orientar-se no campo da Orientação Profissional: contribuições da Fenomenologia
}

\section{Orienting in the field of Career Counselling: Contributions from Phenomenology}

\author{
Me. José Antonio Mesquita Perez \\ jose.perez@docente.unip.br \\ Universidade Paulista - UNIP
}

\section{RESUMO}

O objetivo deste artigo é o de mostrar como a noção de "orientação" é cabível e pertinente ao se pensar a prática da Orientação Profissional dentro de uma perspectiva fenomenológica. Defendemos que nessa área a palavra "orientação" não precisa ser abandonada desde que seja compreendida com um "se orientar". Chega-se à posição de que não está em jogo, num processo de Orientação Profissional, determinar para alguém a profissão que ela deve seguir, mas o de proporcionar um espaço no qual a pessoa é convidada a cuidar de como ela se orienta no seu horizonte de possibilidade. Essa reflexão leva o artigo a pensar sobre o próprio campo da Orientação Profissional e a importância do diálogo em sua constituição, com o intuito de mostrar a relevância de não se segregar deste campo, mesmo havendo concepções e compreensões divergentes de como se entende o fenômeno da escolha profissional nas diferentes abordagens.

\section{ABSTRACT}

The objective of this article is to display how the notion of "orientation" is pertinent when thinking about the practice of Career Counseling within a phenomenological perspective. It is argued that in this area the word "orientation" doesn't need to be abandoned, as long it is understood as "self-orienting". It comes to the position that isn't at play, in the field of Career Counseling, to determine for someone the profession that she or he should follow, but that it is to provide a space in which the clients are invited to care of how they orient themselves in their horizon of possibility. The article also thinks about the field of Career Counseling and the importance of the dialogue to its constitution, with the purpose to indicate the importance of not segregating from this field, even with diverging conceptions and understandings of how the phenomenon of professional choice is understood by the different approaches.

Palavras-chaves: Orientação Profissional. Psicologia fenomenológica. Escolha.

Keywords: Career Counseling. Phenomenological psychology. Choice. 


\section{Introdução}

A temática deste artigo é como a noção do termo "orientar" se apresenta na prática da Orientação Profissional. Deve-se ressalvar que não há uma unanimidade em relação a essa problemática, pois se se considera que o campo da Orientação Profissional é polissêmico, como o “orientar" aparece em cada uma dessas possibilidades de compreensão desse campo também pode ser diferente.

No enfoque chamado traço-fator, por exemplo, o orientar é mais diretivo. Após uma bateira de testes e inventários de interesses, o profissional apresenta para o orientando algumas possibilidades de profissões que são mais adequadas para o perfil dele. Nesse processo, busca-se encontrar um caminho no qual o orientando pode, de modo mais fácil, se adequar e adaptar a uma profissão. Tal abordagem trabalha com a ideia de um sujeito mecânico que não se modifica, ou pouco se modifica, ao longo de sua vida; e com a ideia de um mundo de trabalho que é estável1. Permitindo, dessa maneira, vislumbrar uma maior certeza no momento da escolha profissional.

No entanto, com o desenvolvimento do campo da Orientação Profissional, novas possibilidades de compreender o fenômeno da escolha profissional foram surgindo. Outras abordagens partem de diferentes pressupostos teóricos, epistemológicos e ontológicos.2 E muitas abandonam o objetivo de determinar, ao orientando, qual é a melhor profissão a ser seguida. Tais maneiras de se pensar e fazer Orientação Profissional deixam de entender o ser humano e o mundo de modo mecanicista. Se se entende o mundo como mais flexível e o ser humano em constante desenvolvimento, torna-se mais difícil oferecer certezas para alguém. Portanto, algumas dessas novas abordagens buscaram compreender o orientar de modo mais adequado com essa maneira de se entender o mundo e o humano.

Feijoo, Protasio e Magnan (2014), defendem uma postura do orientador que não seja diretiva, pois o objetivo do processo não é o de dar uma resposta

1 Cf. Ribeiro e Uvaldo, 2011.

2 Cf. Ribeiro e Melo-Silva, 2011a, 2011b, organizadores do Compêndio de Orientação Profissional e de Carreira no qual é apresentado diferentes perspectivas teóricas e práticas de orientação. 
definitiva. Partindo de uma perspectiva fenomenológica - para pensarem a prática da Orientação Profissional - elas possuem o entendimento de existência enquanto uma abertura que evidencia a indeterminação do ser humano. Outro fator presente na proposta das autoras é que a própria pessoa é compreendida como responsável pelo cuidado de si. Concordamos com essas colocações feitas a partir de uma leitura da ontologia fundamental heideggeriana.

No entanto, Feijoo, Protasio e Magnan (2014), vão além e sugerem que o termo orientação não seria adequado para ser utilizado no âmbito do fenômeno da escolha profissional, pois assim haveria uma certa ideia de diretividade. Com esta posição, o presente artigo possui uma posição diferente. O objetivo deste trabalho é o de proporcionar um diálogo com as autoras e, a partir de um outro olhar, apresentar outra maneira de entender o termo orientar, possibilitando refletirmos como este vocábulo pode estar adequado com um enfoque fenomenológica de Orientação Profissional - a saber, pensa-se o orientar como um se orientar.

Defendemos também que mudar o nome de Orientação Profissional para Análise da escolha profissional traz prejuízos para este campo, pois com essa alteração há um movimento de distanciamento das outras abordagens que compõe essa área, de tal modo que prejudica os diálogos e discussões que podem ser estabelecidos com os diferentes modos de compreensão do fenômeno da escolha profissional. Tendo em vista que a Orientação Profissional é caracterizada por um campo de tensões - esse elemento será aprofundado no item dois do presente artigo - alterar o nome do campo não demarca somente uma nova maneira de se pensar a Orientação Profissional, mas também dificulta um dialogar com as outras abordagens. Consideramos que se distanciar dessa tensão (com a alteração do nome) é justamente enfraquecer o próprio campo e a própria abordagem fenomenológica nesse meio.

O artigo está dividido em duas partes. Em um primeiro momento, procuraremos compreender como Feijoo e Magnan (2012, 2013) e Feijoo, Protasio e Magnan (2014) compreendem o orientar (1.1); para permitir a realização de um contraste desse termo com as outras abordagens de Orientação Profissional (1.2) e, por fim, apresentarmos a nossa proposição e visão do orientar, justificando nosso entendimento acerca do termo como adequado para se pensar a Orientação 
Profissional a partir da perspectiva fenomenológica-hermenêutica (1.3). Na segunda parte do artigo será discutido o campo da Orientação Profissional enquanto as tensões de suas abordagens e a importância do diálogo que o constitui na tentativa de fornecer mais um argumento para a não mudança de nome do campo (2).

\title{
1 A noção de (se) orientar e o seu papel na Orientação Profissional
}

\subsection{Análise da escolha profissional: uma breve caracterização}

Feijoo, Protasio e Magnan (2014) descrevem da seguinte maneira como compreendem o trabalho clínico com o fenômeno da escolha profissional:

\begin{abstract}
ao analista da escolha profissional, nessa posição libertadora, cabe não ditar caminhos a seguir, mas aguardar que aquela pessoa, em sua singularidade, possa se abrir para outros sentidos, que, muitas vezes, permaneceram esquecidos ou encobertos pelas orientações sedimentadas de seu mundo, tais como a expectativa de crescimento, de progresso, enfim, de submissão lógica ao mercado. Criar um espaço de libertação ou ampliação de possibilidades que busca esclarecimentos em sua escolha profissional implica em desfazer determinações hegemônicas do nosso horizonte histórico, de modo que se possa não embarcar cegamente no nós das ideias preconcebidas de sucesso e controle [...]. Libertar, portanto, implica em cuidar para que a escolha possa acontecer não somente sob a tutela do mundo abrindo, assim, a possibilidade de criação ou de imersão em outras escolhas possíveis. (p. 61)
\end{abstract}

Percebe-se como neste enfoque o trabalho de Orientação Profissional não é algo diretivo, já que não "cabe ditar caminhos" a serem seguidos. A proposta das autoras é a de que se deve possibilitar ao orientandoz uma reflexão sobre a escolha profissional de um modo em que ele esteja mais em sintonia consigo mesmo do que com verdades e imagens preconcebidas e, que poderíamos chamar de estereotipadas. Libertar é colocar o orientando em contato com o seu ter-que-ser, isto é, colocar o consultado para cuidar e se responsabilizar da decisão de seu futuro profissional.

\footnotetext{
3 Por mais que Feijoo, Protasio e Magnan (2014), utilizam o termo analista, analisando e análise, decidiuse, quando se mostrou pertinente, manter o vocabulário escolhido para a escrita do presente artigo: orientador, orientando e orientação.
} 
O caráter indeterminado da existência é destacado por essa perspectiva; "a indecisão é a condição do homem como abertura frente às possibilidades que lhe são dadas [...]. Dada essa condição de indeterminação prévia e de aberturas próprias ao existir, não cabe falar em potencial, vocação ou aptidão [...]” (Feijoo, Protasio e Magnan, 2014, p. 59). Desse modo, não há o intuito de “[...] garantir, dar certezas, promover escolhas seguras, êxito e sucesso, aos quais esse profissional acede a partir de suas técnicas, na medida em que desvela o potencial escondido e a verdade que se encontrava por trás do que se apresenta" (Feijoo, Protasio e Magnan, 2014, p. 61). Todavia, procura-se “[...] realizar uma desconstrução das estruturas prévias, as quais, por vezes, encobrem o que lhe é mais original a indeterminação" (Feijoo e Magnan, 2012, p. 361).

O que as autoras estão defendendo é que o trabalho do orientador não é o de direcionar o orientando, mas o de analisar o processo da escolha profissional de quem está sendo atendido. O objetivo é proporcionar um espaço que possibilite o orientando: reconstruir posições prévias, descontruir as posições prévias e, assim, permitindo um construir fenomenológico que oferece ao orientando um poder se apropriar dos sentidos que estão implicados na sua escolha profissional.4

Pode-se afirmar que essa perspectiva entende a Orientação Profissional como um processo relacional, de tal maneira que o orientador não é visto como neutro, mas integrante do processo. Ou seja, o que está em jogo nesse trabalho analítico e interpretativo "[...] são os encontros de horizontes [do analisando e do analista], que consistem precisamente no que se fala e se escuta, a partir de uma relação intencional [...]. O que o analisando diz vai ser escutado a partir do horizonte compreensivo do analista, porém o analisando sempre é a medida" (Feijoo e Magnan, 2012, p. 370).

Destaca-se alguns elementos que podem sistematizar alguns pontos relevantes dessa abordagem:

(1) Feijoo e Magnan (2012, 2013) e Feijoo, Protasio e Magnan (2014), substituem o termo orientação pelo termo análise com o intuito de evidenciar que não é papel do orientador direcionar a escolha do orientando;

${ }_{4}$ Cf. Feijoo e Magnan, 2012, pp. 362-370 e Feijoo e Magnan, 2013, item: 3.4. 
(2) é salientado a indeterminação da existência, sendo que parte do processo de Orientação Profissional é possibilitar aos jovens a confrontação com essa indeterminaçãos e, acrescentaria, refletir em como lidar com essa questão;

(3) por mais que a "medida" que pauta os encontros sempre é o orientando, reconhece-se que o falar e o escutar do orientador está relacionado com o seu próprio horizonte compreensivo6. Isto é, o profissional da orientação não é tido como neutro;

(4) destaca-se que a análise proposta por essa perspectiva está centrada em um processo de desconstrução que visa proporcionar ao orientando uma visão mais apropriada daquilo que está implicado na sua escolha profissional e não por uma teoria.

\subsection{O orientar na Orientação Profissional}

Pensa-se que o orientar não precisa necessariamente ser negado, pois ele não é em todos os casos um direcionamento feito por outrem. $\mathrm{O}$ intuito deste item é o de justamente mostrar, como dentro do campo da Orientação Profissional, o orientar e a diretividade não são, necessariamente, entendidos como sinônimos.

Bohoslavsky (2015) diferencia duas modalidades no campo da Orientação Profissional: (a) estatística; (b) clínica.

(a) A primeira é caracterizada como um processo psicométrico que tem o intuito de através de instrumentos de avaliações e testes psicológicos conhecer o indivíduo e, por conseguinte, determinar o "melhor caminho possível” a ele. Desse modo, "o teste é o instrumento fundamental para se conhecer as aptidões e interesses [do cliente]. Parece descrever com rigor as qualidades pessoais do interessado e, uma vez feito isso, basta formular um conselho que resuma o que, ao jovem 'lhe convêm fazer"' (Bohoslavsky, 2015, p. 3, grifo nosso). Portanto, observa-se a feição do direcionamento determinado por outrem nesta modalidade.

(b) Já na modalidade clínica, o objetivo não é aconselhar o orientando a partir de testes e diagnósticos, mas em possibilitar o jovem em “[...] assumir a situação que enfrenta e, ao compreendê-la, chegar a uma decisão mais responsável”

${ }_{5}$ Cf. Feijoo e Magnan, 2012, 2013; e Feijoo, Protasio e Magnan, 2014.

${ }_{6}$ Cf. Feijoo e Magnan, 2012, p. 370. 
(Bohoslavsky, 2015, p. 3, grifo nosso). Nesta modalidade, diferentemente da modalidade estatística, observa-se a feição da autonomia; preza-se pela responsabilidade e pelo cuidado de si da pessoa. Bohoslavsky (2015) afirma que essa diferença de ponto de vista entre ambas implica numa questão ética. "A ética surge do fato que, ao considerar o homem sujeito de escolhas, consideramos que a escolha do futuro é algo que lhe pertence e que nenhum profissional, por capacitado que esteja, tem o direito de expropriar" (Bohoslavsky, 2015, p. 21). Uma das dimensões dessa implicação ética é chamada pelo autor de filosófica; aqui está em jogo a compreensão do ser humano, não somente a partir de uma visão cientificista; todavia, levando em consideração “[...] a vida real e concreta dos seres humanos, e a análise da liberdade [...]" (Bohoslavsky, 2015, p. 22).

Percebe-se que a abordagem clínica desenvolvida por Bohoslavsky (2015) na argentina, por volta dos anos 1970, não visa direcionar o orientando, pelo contrário, considera a autonomia do jovem e leva em conta a questão da liberdade. Indicando que o orientar é compreendido de uma maneira diferente de diretividade. Isso, de certa forma, é aproximável com a perspectiva da Análise da escolha profissional. Se Bohoslavsky falava de um processo que permite o orientando assumir a situação que enfrenta (nesse caso o da escolha profissional), a perspectiva da Feijoo e Magnan (2012, 2013) e Feijoo, Protasio e Magnan (2014) diz do processo enquanto a possibilidade do analisando assumir sua indeterminação. O que está posto, em ambas as abordagens, não é o orientador determinar o caminho de alguém, mas possibilitar que o orientando possa lidar consigo mesmo e com a decisão por efetivar de um modo mais apropriado e responsável.

Bohoslavsky (2015), coloca uma outra temática para se ponderar em relação ao processo de Orientação Profissional e que também é aproximável a uma perspectiva fenomenológica: a importância que o futuro como um todo adquire no processo. Isso configura uma determinada maneira de se compreender a finalidade da Orientação Profissional; o peso de sair do processo de orientação com uma decisão efetiva de uma profissão a se seguir é diminuído. A deuteroescolha é priorizada: "talvez mais importante do que levar a termos a escolha de uma carreira seja levar a bom termo a escolha de um futuro (seja estudo ou trabalho). A 
diferença acha-se na aprendizagem de como escolher [...]” (Bohoslavsky, 2015, p. 96). Então, pode-se pensar que o mais importante no processo de Orientação Profissional não é necessariamente a escolha efetiva de uma carreira, mas como o orientando lida com as suas perspectivas futuras. De modo semelhante, Feijoo, Protasio e Magnan (2014), ao refletirem sobre o existencial do Cuidado (Sorge) de Heidegger (2012), apontam que "[...] o analisando pode chegar ao final do processo até mesmo sem uma escolha profissional definida, mas em liberdade para assumir a sua decisão" (Feijoo, Protasio e Magnan, 2014, p. 73). Vemos aqui uma preocupação semelhante com a abordagem de Bohoslavsky, pois o mais fundamental deixa de ser a escolha de uma profissão e passa a ser como é o cuidado do orientando consigo mesmo e sua maneira de estar no mundo.

A partir dessas reflexões, pode-se esboçar algumas aproximações dessas duas abordagens. Poder-se-ia resumir dizendo: ambas não buscam direcionar, mas possibilitar que o orientando se aproprie ou responsabilize por si mesmo de maneira autônoma. No entanto, podemos dizer que há uma diferença crucial entre as duas. Essa se encontra justamente na questão de como a análise faz parte do processo em cada um desses enfoques. Diferentemente da perspectiva da Análise da escolha profissional, a modalidade clínica de Bohoslavsky apresenta um viés psicanalista no qual a escolha de uma carreira será entendia como a reparação de um objeto interno7. A Análise da escolha profissional não parte de alguma teoria $a$ priori para embasar sua análise, mas de uma metodologia, neste caso, a fenomenológica. Este modo de proceder na Análise da escolha profissional reforça a posição assumida por Bruns (1992) em sua pesquisa sobre escolha profissional em estudantes universitários. A pesquisadora, partindo de um método fenomenológico não considera de antemão teorias da subjetividade; sendo que na pesquisa não se visava o "sujeito" que escolhe, mas a experiência do escolher, isto é, o foco se dá no fenômeno da escolha.

\footnotetext{
7 Não entraremos nos pormenores desse entendimento, por não ser o escopo deste trabelho, para uma visão mais detalhada, conferir Bohoslavsky (2015).
} 
Além da perspectiva de Bohoslavsky (2015), há outras abordagens no campo da Orientação Profissional que também não compreendem o termo orientação como um direcionar alguém. 8

Um desses enfoques é o contextualista baseado na teoria da ação 9 . Segundo Ribeiro (2011), em tal abordagem, o principal objetivo é permitir que a narrativa de vida possa ser elaborada por significações que permeiam as ações e contextos relacionados à carreira e, assim, pensar em projetos possíveis para o futuro profissional do orientando. Sendo que dois dos principais idealizadores dessa perspectiva afirmam que, a partir da narrativa do cliente, "o orientador se junta no desenvolvimento de tais narrativas, mas respeita a liderança do cliente" (Valach e Young, 2002, p 108, nossa tradução)10. Ou seja, observa-se um orientar que também respeita a autonomia do orientando. $\mathrm{O}$ orientador não é aquele que controla a decisão do paciente. O foco se dá na relação orientador/orientando de modo que o processo é uma co-construção; o orientador tem o papel de problematizar11 aquilo que está em questão no processo de orientação permitindo que o orientando consiga significar as temáticas e questões relacionadas à escolha profissional.

Outro enfoque que também não considera o orientar como algo diretivo é a Teoria da Ativação do Desenvolvimento Vocacional e Pessoal. Segundo Teixeira (2011), os principais autores, Pelletier, Noiseaux, Bujold (1974), buscam a ativação dos processos operatórios envolvidos nas questões vocacionais; assim sendo, a prática consiste em propor exercícios vivenciais que busquem o estímulo desses processos cognitivos, possibilitando que tais vivências possam ser integradas com a história individual da pessoa que passa por esse processo. Observa-se que nessa abordagem também não se direciona alguém para algum determinado caminho que o orientador (ou algum teste) acredite que seja o melhor para uma determinada pessoa; todavia, há aqui uma procura em auxiliar o

\footnotetext{
8 Não iremos aprofundar em cada um desses diferentes enfoques, mas brevemente apresentar como o orientar se encontra presente nessas e abordagens e como podemos interpretar seu entendimento.

9 Para um maior entendimento geral desta perspectiva, conferir Ribeiro (2011).

10 "the counsellor joins in developing such narratives but respects the leadership of the client".

${ }_{11}$ Cf. Ribeiro, 2011.
} 
orientando (através das ativações de processos cognitivos específicos da escolha) a aprender a escolher e que ele se torne mais "capacitado" para lidar com suas decisões.

Também se destaca as contribuições socioconstrucionistas de Ribeiro e Lehman (2011). Eles, partindo de uma compreensão de mundo sociolaboral que é mais flexível, heterogêneo e fragmentado na atualidade, entendem que a noção de carreira também precisa acompanhar este atual contexto. Sendo assim, torna-se difícil propor um processo de Orientação Profissional que não considere esses aspectos. Eles defendem que, por conta dessa maior instabilidade, as mudanças e transições que uma pessoa encara ao longo de sua trajetória no mundo laboral é maior. Desse modo, o objetivo de um processo de Orientação Profissional, nessa perspectiva, deve ser o de proporcionar ao sujeito uma instrumentação que o permita a lidar com esses momentos de transição que sofre e/ou sofrerá ao longo de sua carreira. Não se limita ao âmbito do fazer ou do escolher a ocupação, mas o processo de orientação trabalha com estratégias identitárias que podem auxiliar o orientando na construção de projetos ocupacionais nos momentos de transição 12. Percebemos, novamente aqui uma posição do orientador que busca proporcionar ao orientando um espaço para se desenvolver e refletir sobre si e como ele se coloca frente as situações que enfrenta e não como um espaço no qual será ditado caminhos e regras a serem seguidos.

Um ponto comum das abordagens postas anteriormente é a postura do orientador não diretiva. As diferenças (e que aqui, por conta do escopo do trabalho, não foi detalhado) que podem ser encontradas entre as abordagens é que as teorias e metodologias de cada uma são diferentes.

Como era discutido, as autoras da Análise da escolha profissional de algum modo se aproximam dessas abordagens ao defenderem o não direcionar no processo de Orientação Profissional. No entanto, talvez, a contribuição mais significativa que essa abordagem traz para o campo da Orientação Profissional, numa perspectiva clínica, seja a crítica em relação as compreensões a priori do ser humano e mundo que podem ofuscar o entendimento daquele que se encontra em atendimento em um processo de orientação. Tal crítica está em consonância em

${ }_{12}$ Cf. Ribeiro e Lehman, 2011, item: 2.1.2.1. 
como a fenomenologia aparece no cenário da Orientação Profissional. Como já mencionado Bruns (1992) compartilha dessa questão relacionada ao acesso ao fenômeno da escolha profissional. No entanto, o trabalho da autora é delimitado ao âmbito da compreensão do fenômeno e não à uma práxis clínica.

Outra articulação entre a Orientação Profissional e a Fenomenologia é a da Selma Garrido Pimenta (1979). Em sua dissertação de mestrado (1979), ela parte de uma crítica ao psicologismo e ao sociologismo no campo da Orientação. A fenomenologia-existencial entra como uma tentativa de escapar desses dois “ismos", pois "a dissecação psicológica da decisão, sempre colocou o homem como determinado — biológica ou socialmente [...]" (Pimenta, 1979, p. 42). Nesse trabalho a autora busca por uma compreensão de ser humano e um entendimento de decisão que estejam adequados com a totalidade da existência. No entanto, Pimenta (1979) chega à conclusão que "a orientação profissional vai à filosofia buscar soluções para o problema da decisão e lá fica” (p. 55). A autora acaba, de certo modo, abandonando o caminho que trilhou na dissertação. No entanto, defendemos que se cai em um filosofismo somente quando aquele que vai até a filosofia deixa de dialogar com os contextos concretos nos quais o ser humano enquanto ser-no-mundo está inserido. A critica, levantada por Pimenta, sobre o risco em não se levar em consideração o momento histórico e a sociedade em que o processo de orientação se dá, é importante e deve ser levada em consideração; todavia, isso não significa que, necessariamente, a fenomenologia em todos os casos está fadada a este destino. Pensa-se, dessa maneira, que o trabalho de Feijoo e Magnan (2012, 2013) e Feijoo, Protasio e Magnan (2014) é uma maneira possível de se recorrer a fenomenologia sem cair em um filosofismo, pois as autoras também consideram os aspectos históricos para se pensar o fenômeno da escolha profissional.

Por fim, defende-se que uma abordagem de Orientação Profissional fenomenológica pode ser enriquecida e contribuir mais com esse campo caso haja um diálogo entre essas diferentes teorias e metodologias. A noção de identidade é um exemplo que podemos utilizar para demostrar isso. No campo da Orientação Profissional diferentes autores (Guichard, 2004; Ribeiro, 2014; Delory-Momberger, 2004) falam de algum tipo de processo identitário. Pensa-se 
que a Fenomenologia pode contribuir para se pensar essa13 e outras questões; não necessariamente para concordar com tudo que é afirmado sobre essas temáticas, mas, às vezes, para criticar, problematizar e construir novas noções sobre os fenômenos estudados neste campo.

Outro exemplo de como esse diálogo pode se dar é a proposta do próximo subitem deste artigo: a tentativa de indicar uma outra noção de orientação e do orientar a partir de uma perspectiva fenomenológica-hermenêutica. Essa noção não é totalmente nova, mas é a articulação da noção de orientar não diretiva - tal como apresentado anteriormente pelas diferentes abordagens - com o termo sentido, sendo este compreendido por uma leitura fenomenológica que é fundamentada por Critelli $(2007,2016)$.

\subsection{Orientar: uma proposição de sua posição na Orientação Profissional}

Segundo Guichard (2004), “O indivíduo 'orienta a sua vida' e se relaciona consigo mesmo em uma sociedade dada: esta, porque é organizada de uma certa maneira, fornece a ele referências - 'estruturas sociais' - nas quais ele se constrói de uma certa maneira" (p. 2, tradução nossa, grifo nosso) 14. Destaca-se que, na citação anterior, o termo orientar não aparece somente de uma maneira que referência si mesmo e mundo, entretanto, referencia um direcionamento. A maneira como alguém organiza a sua vida está relacionado com o modo dela se colocar e estar no mundo, ou, nas palavras do autor da citação, está conectada em como alguém orienta a sua vida numa sociedade em que se encontra inserido. Orientar está de algum modo conectado com o significado de direcionamento, mas, como começamos a perceber, um direcionar que se refere a como a pessoa está se posicionando no mundo e não como um "conselho" ou uma diretividade proveniente do social ou do outro.

\footnotetext{
13 A noção de identidade é discutida na obra de Reis (2014), sendo que ele utiliza termos como "individuação existencial" (p. 89) e "identidade existencial" (p. 165), por exemplo.

14 "L'individu « oriente sa vie » et se rapporte à lui-même dans une société donnée: celle-ci, parce qu'elle est organisée d'une certaine manière, lui fournit des repères - des «cadres sociaux»dans lesquels il se construit d'une certaine manière".
} 
Essa noção de orientar se encontra coerente com uma noção fenomenológica de sentido que pode ser entendido, justamente, como direção. Segundo Critelli (2007), “[...] a vida humana está em perpétuo deslocamento. Viver como homens é jamais alcançar qualquer fixidez" (p. 17). Ora, se o ser humano sempre está em deslocamento, também se considera que ele está indo para uma determinada direção. Ou seja, sempre se está caminhando num determinado sentido.

Sentido, portanto, adquiri uma conotação particular: "[...] não como expressão sinônima de significação. Sentido é, para nós, o mesmo que destino, rumo, a direção do existir" (Critelli, 2007, p. 57). Com esse termo está em jogo um se destinar, ou, poderíamos dizer, um se orientar. Por sua vez, a palavra orientação, em diversos casos, é utilizada justamente com um significado que referencia direcionamento. Espacialmente pode-se estar orientado para o norte, para o sul, para o leste, ou para o oeste. Outro exemplo: uma pessoa que está estudando e se preparando para um vestibular está orientando sua vida para entrar numa instituição de ensino superior. Podemos pensar também no termo desorientação: que é utilizado quando alguém perdeu seu rumo, ou não consegue achar seu caminho - seja isso de modo efetivo e concreto; seja de modo simbólico, como no caso, por exemplo, de alguém enlutado15. Portanto, se orientar pode ser compreendido como um se direcionar. Com isso, poderíamos afirmar que uma pessoa a cada momento se encontra orientada para algum determinado sentido fazendo referência em como a pessoa se compreende, como será mais trabalhado a seguir.

Propõe-se quatro reflexões diferentes que contribuem para a compreensão da noção do se orientar a partir de uma perspectiva fenomenológica.

(1) Deve-se considerar que esse se direcionar se dá num mundo que é concreto e significativo, pois a todo momento estamos nos relacionando com as coisas e os outros. Uma coisa não é em si mesma significativa, mas somente e a

15 Por exemplo, Busa, Silva e Rocha (2019), num artigo de luto sobre jovens adultos que lidam com a perda pelo câncer de pais afirmam que é comum a vida dos jovens ficar desorientada (p. 4 e 5). 
partir do momento que ela se encontra historiada pelas pessoas 16 que ela adquire sua significatividade. Ou seja, "temos a ilusão que moramos num mundo significativo em si por si mesmo. Mas em si mesmo o mundo é nada, é pura coisa. Nossa linguagem torna o nada da pura coisa num mundo" (Critelli, 2016, p. 33). Assim, o se orientar se enlaça em como nos posicionamos no mundo e como para com ele nos relacionamos.

(2) No entanto, estar em um mundo, sempre é estar com o outro de modo originário17; "nossa participação em um contexto social é, então, uma dimensão fundamental de nossa existência" (Guignon, 1993, p. 226, tradução nossa)18. O componente social ganha importância no se orientar já que é habitando um mundo e com os outros que se existe. Na maior parte das vezes, são com os outros que nos direcionamos, não no sentido que, necessariamente, duas ou mais pessoas se projetam ao futuro da mesma maneira, mas que no nosso horizonte de possibilidade o outro, de alguma maneira ou de outra, se faz presente.

(3) O nosso modo-de-ser não é representacional19 mas operacional (ou operativo)20. Partindo da perspectiva da ontologia fundamental heideggeriana, conhece-se o mundo através do modo como se lida com ele; “[...] a maneira fundamental que temos e encontramos nosso mundo é pré-cognitivo e consiste em cuidados hábeis, familiares, dispostos, intencionais" (Käufer e Chemero, 2019, p. 58, tradução nossa)21. Para nossa reflexão sobre a noção de orientar, esse modo de se relacionar com o mundo implica que o se orientar não será visto como uma operação meramente mental ou simplesmente uma escolha que fazemos através de

\footnotetext{
16 "Quando um giz é desvelado, quando ele é manifesto como o ente que é, nada ocorre nele, não entra em cena nele nenhum processo natural, e, todavia, acontece algo com ele: ele entra em uma história" (Heidegger, 2009, p. 110)

17 Cf. Critelli, 2007, 2016.

18 "our participation in a social context is therefore a fundamental dimension of our existence"

${ }_{19}$ Cf. Wrathall, 2005.

20 Cf. Reis 2000; Kaufer e Chemero, 2019.

21 "[...] the fundamental way we have and encounter our world is pre-cognitive and consist of skillful, familiar, disposed, purposive caring".
} 
processos cognitivos e representacionais, mas como uma maneira de estar sendo no mundo e, então, poderíamos dizer: uma maneira de cuidar22 de quem se foi, quem se é e de quem se quer ser. $\mathrm{O}$ orientar remete a como o cuidado consigo mesmo é exercido na vida de alguém.

(4) Por fim, se orientar envolve de modo integrado o passado, o presente e futuro. Sabe-se que, partindo de Heidegger (2012), o vir-a-ser (futuro) adquire uma posição de destaque frente aos outros dois "tempos". Em Ser e Tempo, há a questão do projeto; esse está relacionado com um estar lançado em possibilidades. A todo momento o ser humano se compreende enquanto possibilidade, is to é, ele está num horizonte que o abre para possíveis maneiras de ser. Ontologicamente, poderíamos afirmar que sempre, de algum modo ou de outro, nos encontramos orientado para um certo horizonte de possibilidade, pois não se trata daquilo que se efetiva ou das possibilidades que podem ser concretizadas, mas que sempre o ser humano, se entendido enquanto ser-aí, compreende-se enquanto possibilidade (Reis, 2014). Desse modo, entende-se que o ser humano se encontra lançado para o futuro enquanto possibilidade de ser e isso influência como ele compreende aquilo que já fez na sua vida e como ele age no presente.

É uma vida que é focalizada por seu direcionamento futuro [...]. Esse direcionamento para a culminação de nossas vidas nos permite apropriar o que já aconteceu como recursos ou valores cuja significância latente é trazida à realização através de ações no presente. (Guignon, 1993, p. 230, nossa tradução) 23

Portanto, pode-se afirmar que se orientar não abarca somente como nos encontramos direcionados para o futuro, mas também envolve como entendemos a nossa história e nossas ações presentes.24 Colocando com outras palavras, num

$22 \mathrm{O}$ aspecto do Cuidado ganha relevância nos trabalhos de por Feijoo e Magnan $(2012,2013)$ e Feijoo, Protasio e Magnan (2014).

23 "It is a life that is given focus by its future directedness [...]. This directedness toward the culmination of our lives lets us appropriate what has already happened as resources or assets whose latent significance is brought to realization trough action in the present".

24 Ressalva-se que o ato de se orientar não é algo que precisa ser necessariamente consciente, mas de algum modo ou de outro já estamos orientados, isto é, direcionados para horizonte de possibilidade. 
âmbito ôntico, dependendo de como alguém se encontra orientado para o seu futuro, determinará como ela se compreende atualmente e como ela entende a sua história.

A questão — como muito bem apontada por Feijoo e Magnan (2012, 2013) e Feijoo, Protasio e Magnan (2014) — é que, no processo de Orientação Profissional, o orientar não deveria estar exclusivamente determinado por outrem. Todavia, neste processo, a orientação está relacionada em como aquele que está em atendimento se vê e se projeta no mundo e com os outros. A singularidade e responsabilidade pela própria existência não podem ser abandonadas na Orientação Profissional. O artigo também compartilha da posição de que o orientando não pode ter a tarefa por ser quem ele mesmo é diminuída; portanto, o orientador deve estar pautado pela preocupação libertadora e não pela substitutiva25.

Assim sendo, um orientar está em jogo na tomada de decisão de uma profissão. Pois, o orientando está ali pensando e repensando a direção e o sentido que ele quer tomar no seu futuro profissional26. É a possibilidade de refletir sobre o próprio destino ou, com outros termos, ponderar sobre o seu próprio rumo.

Para ilustrar esse posicionamento, a reflexão sobre um mapa pode ser utilizada como analogia para pensarmos o sentido do termo orientar no processo de Orientação Profissional. Ao precisarem se locomover, muitas vezes, as pessoas recorrem a mapas — sejam físicos ou digitais — para se orientarem caso não saibam qual caminho a de tomarem. No entanto, não é o mapa que diz onde a pessoa quer e/ou tem que chegar, não é este que diz qual o melhor caminho que deve ser seguido, muito menos diz qual dos caminhos é mais ou menos seguro. Em outras palavras, o mapa não direciona; ele simplesmente possibilita a pessoa que o utiliza visualizar quais são as opções de trajetos que se encontram disponíveis, para ela poder escolher qual rumo irá tomar. Este instrumento, portanto, possibilita quem o utiliza a cuidar do caminho que irá seguir; permitindo a pessoa ter mais clareza do que ela pode encontrar em sua jornada. Tal como um mapa, a Orientação Profissional não deve escolher o destino que alguém quer chegar, mas o de

25 Para um maior aprofundamento, conferir: $§ 26$ de Ser e Tempo, Heidegger (2012), p. 341.

26 Não exclusivamente profissional, mas considerando outros aspectos e âmbitos de sua vida que de alguma maneira influenciam em como o projeto profissional de alguém será entendido. (Almeida, 2008). 
possibilitar um espaço no qual a pessoa possa se orientar de uma maneira que lhe seja mais própria e responsável.

Desse modo, pensa-se que o trabalho da Orientação é o de possibilitar ao orientando um (re)pensar a sua história, o seu presente e o seu futuro. Aqui pode muito bem entrar a análise proposta por Feijoo e Magnan (2012, 2013) e Feijoo, Protasio e Magnan (2014)27: através da reconstrução, destruição e construção fenomenológica, o orientando está na realidade revendo aquilo que é significativo ou não para ele. O foco da Orientação Profissional é o de proporcionar que a pessoa possa cuidar dos seus projetos. O papel do orientador nesse processo é o de criar espaços para a apropriação de si mesmo e do mundo.

Se se entende que para a fenomenologia o ser humano é

[...] destinado ao Cuidado (Sorge). [A fenomenologia] é uma filosofia para a qual o homem é um poder-ser aberto em possibilidades, mas limitado pelo não poder tudo e pela finitude, destinado a realizar sua existência no mundo fático que é o dele, sempre devedor à existência. (Sapienza, 2013, p. 13)

Como dito, essa tarefa do existir não pode ser delegada a alguém. Entrementes, o chamado para esse cuidado é algo que pode ser apropriado no processo de orientação. E só nesse sentido podemos falar de um orientar do orientador: não o de direcionar caminhos seguros e claros; todavia, o de proporcionar um possível caminho para o cuidado de si e do seu futuro.

Feijoo, Protasio e Magnan (2014), afirmam: “análise diz respeito ao fato de que a atividade de analis ar consiste em levar aquele que se encontra indeciso, ou busca certezas, a destecer verdades estabelecidas pelo mundo [...]” (p. 60, grifo nosso). Pode-se destacar que, se analisar é constituído por um levar alguém à certo movimento (no caso: destecer verdades); ele também é, de algum modo, um

\footnotetext{
${ }_{27}$ Desde que se leve em consideração que o orientando seja visto a partir de sua totalidade e não de "partes" diferentes. A ressalva que Pompéia (1978) faz para o encontro psicoterapêutico também vale para o encontro de Orientação Profissional: "[a pessoa] não fica reduzida ao sentido analítico, que decompõe a totalidade da pessoa em problemas objetivos, parcelados, e considerados isoladamente, a ponto de fazer desaparecer ao horizonte a própria pessoa. A pessoa sentada a nossa frente num encontro terapêutico, não é uma colcha de retalhos, de eventos e problemas independentes. É uma totalidade" (p. 75).
} 
orientar alguém — ora, quem está levando, também indica um certo caminho. Só que onde se chega não é necessariamente um lugar determinado e definido por aquele que orienta; pelo contrário, o levar e o orientar devem ser tomados como um caminhar. A Orientação Profissional leva e orienta o orientando para o cuidado de seu futuro e para o cuidado de si mesmo, qual cuidado? Não há um específico, mas diferentes modalidades de se cuidar. Ressalva-se que esse cuidado não é um destino, no sentido de que se fizermos certas ações e tivermos certas atitudes chegaremos a um cuidar de nós mesmos; todavia, a todo momento cuidamos de nosso próprio ser — tal como é explanado por Heidegger (2012) - menos na modalidade do des-cuidar. Aqui parece ser pertinente a noção de liberdade apresentada pelas autoras.

Freitas, ancorada por Berlin (1958), fala de duas definições diferentes de liberdade: uma negativa e outra positiva. A primeira diz respeito a estar livre de algo restritivo — sua definição se dá por um não estar preso, por isso é denominada de negativa. A segunda diz respeito a estar livre para algo. A primeira definição de libertar pode fazer parte de um processo psicoterapêutico e, muitas vezes é uma etapa necessária; contudo, para além dele, a autora afirma: "a liberdade de dedicar-se ao sentido é o próprio horizonte da terapia [...]” (Freitas, 2011, p. 81). Defendo que podemos transpor esse modo de pensar a terapia para se pensar a Orientação Profissional: como o lugar do orientando poder exercer sua liberdade de cuidado pelo sentido.

\section{Orientação Profissional: seu campo e sua tensão28}

Uma outra tarefa que o presente artigo agora empreende é o de pensar o campo da Orientação Profissional e da importância do diálogo entre as diferentes vozes que o compõe. O objetivo é fazer algumas indicações que possibilitem uma reflexão sobre esse campo como um todo.

${ }_{28}$ Gostaria de agradecer o Professor Doutor Mário de Souza Costa que, através de conversas, me ajudou a vislumbrar a importância da tensão no campo da Orientação Profissional. 
A Orientação Profissional é um campo que não possui de modo unânime uma metodologia e procedimentos. Na realidade, ela é diversa, com diferentes teorias e abordagens. Isso implica numa multiplicidade de visões e modos de compreensões do fenômeno da escolha profissional, como também implica em diferentes metodologias e modos de procedimentos de atendimentos clínicos e pedagógicos em Orientação Profissional. Ribeiro e Melo-Silva (2011a, 2011b), organizadores do Compêndio de Orientação Profissional e de Carreira, mostram diferentes teorias e abordagens dentro da área da Orientação Profissional a partir de diferentes demandas chaves; desde o enfoque do traço-fator até a abordagem socioconstrucionista. No compêndio podemos ver a diversidade e riqueza que compõe esse campo.

Ora, se o campo da Orientação Profissional é diverso, as diferentes abordagens estão, de uma maneira ou de outra, em relação. Pode-se dar um passo além: essa relação, possivelmente, é composta de uma tensão que é criada a partir das diferentes maneiras de se pensar os fenômenos que estão relacionados com a escolha profissional. Com uma outra terminologia, poderia ser afirmado que nesse campo as diferentes perspectivas estão em um jogo, sendo que aquilo que está sendo jogado é o entendimento que se tem dos fenômenos relacionados às escolhas profissionais. Essas afirmativas podem ser sustentas a partir de, pelo menos, duas considerações realizadas com base no pensamento foucaultiano.

(1) Um primeiro ponto que pode ser destacado e que é abordado no pensamento foucaultiano é a relação entre saber e poder na produção das verdades. Cada época pode ter discursos que são qualificados e que funcionam de modo normativo, influenciando no aceite de algumas "verdades" e na exclusão de outras. Aqui aparece, portanto, tal como ressalva Muchail (2004), uma tematização da verdade não a partir de um conceito universal e absoluto, mas como produto de um contexto histórico.

(2) Um segundo ponto, é como podemos entender as tematizações, que usualmente são chamadas de arqueológicas, das Ciências Humanas realizadas por Foucault. Segundo Muchail, a questão para o filósofo francês não são regras formais relacionadas a inteligibilidade dos discursos, todavia, aquilo que condiciona em uma certa época e sociedade o aparecimento, o ocultamento e as 
transmutações dos discursos presentes nessas Ciências. O termo jogo de regras é utilizado para contextualizar as condições de possibilidades do discurso. Sendo assim, “pode-se chamar a esse 'jogo de regras' de epistéme de uma época, [...] o solo onde são constituídas as formações discursivas historicamente realizadas e que compõem as diferentes configurações no espaço do saber" (Muchail, 2004, p. 12).

Levando essas reflexões para o âmbito da Orientação Profissional, pode-se entender este campo como um "jogo" que a todo momento coloca em questão os discursos dos diferentes enfoques e perspectivas que se dispõem a compreender os fenômenos relacionados as escolhas profissionais. Poderia ser dito que o mais importante não deveria ser a determinação de um objeto único, de um método único, de procedimentos únicos para a Orientação Profissional; todavia, seria o diálogo e jogos estabelecidos por essas perspectivas. Pois, seria a partir da troca e da tensão entre os enfoques que o campo se constitui.

Assim, o próprio campo não é composto por uma verdade absoluta, mas por verdades que se modificam de época em época. Sendo que o diálogo, proveniente da tensão entre as abordagens, também possibilita a transmutação das verdades que compõe esse campo. Talvez, o ponto crucial seja como essa tensão é compreendida e significada. Pode-se pensar em pelo menos duas possibilidades: uma na qual essa tensão é vista como algo não aceitável e que deve ser diminuída; ou uma segunda na qual a tensão é usada pelas diferentes abordagens como uma maneira de repensar a própria teoria, prática e/ou ontologia. Essa segunda possibilidade se apresenta como mais agregadora para os diferentes enfoques, pois com problematizações, questionamentos e críticas — que surgem com a tensão — as abordagens são convidadas a reverem seus sistemas e concepções.

O desenvolvimento de um determinado saber, que muda com o tempo em diferentes circunstâncias históricas não implica, necessariamente, num avanço; ou seja, as transformações do saber não são sinônimo de progresso29. Desse modo, o desenvolvimento do campo da Orientação Profissional não progride num sentido de chegar mais perto de uma "verdade" mais "verdadeira" — já que, como 
comentando, são verdades que estão em jogo. Portanto, em um campo em constante (re)formulação, o diálogo30 se torna fundamental.

Nesse constante mudar há de se ter cuidado com algumas questões. Principalmente com os discursos dominantes de uma época e cultura. Uma ressalva feita por Muchail sobre as Ciências Humanas ao proporem estudar o ser humanos, pode ser estendida para a Orientação Profissional:

[...] uma vez que a racionalidade do saber científico é erigida como critério exclusivo da validade de todo saber e medida do verdadeiro, as ciências humanas carregam em seu próprio bojo o risco inalienável da redução do homem ao que dele se pode "cientificamente conhecer". (Muchail, 2004, p. 55)

O risco, portanto, ainda segundo a autora, é de uma soberania de um tipo de saber que invalida os demais saberes como não verdadeiros. Algo que tem confluência, de algum modo, com o pensamento heideggeriano, pois Heidegger não advoga por um abandono das ciências, todavia, ele questiona

[...]a pretensão absolutista da ciência, que assume para si a prerrogativa de parâmetro exclusivo de tudo o que é verdadeiro no mundo, mantendo-se cega para os pressupostos ontológicos que fundamentam seus procedimentos metodológicos, os quais, por sua vez, podem revelar-se perigosos para a humanidade. (Duarte, 2004, p. 32)

Pensa-se que se deve buscar evitar uma hegemonia que não abre espaço para diferentes conhecimentos de um mesmo fenômeno. Defendemos um campo de conhecimento de Orientação Profissional que abrace diferentes modelos, teorias e práticas. Ressalva-se que abraçar não é necessariamente aceitar tudo, mas não silenciar discursos diferentes; como não é misturar as diferentes perspectivas, mas conviver com estas. Isso de certo modo é algo que já acontece, foi indicado em diferentes momentos deste artigo, por exemplo, de que esse campo expressa diferentes vozes. No entanto, talvez seja interessante um cuidado para que não se esqueça desse diálogo e que, assim, ele seja valorizado.

30 Lembro aqui, a partir de Clark e Holquist (2008, p. 35), que no pensamento de Bakhtin há uma diferenciação do dialítico e do dialógico: enquanto o primeiro está pautado por uma lógica do ou em que há uma oposição binária entre diferentes elementos; o dialógico está pautado pela lógica do ambos/e, isto é, os diferentes são aceitos. 
Como já foi mostrado pela literatura deste campo, "primeiro" veio a prática e "depois" veio a teoria da Orientação Profissional; o que aconteceu foi que a Orientação surgiu como a tentativa de responder questões emergentes de uma sociedade, relacionadas ao ingresso de pessoas no mercado de trabalho priorizando-se técnicas e não estudos teóricos dessa temática (Ribeiro, 2011a; Beck, 1977). Beck (1977) também ressalta a falta de interesse, pelo menos no início dessa área do conhecimento, em se pensar e conduzir estudos sobre os fundamentos filosóficos que estão implicados nesse campo.

Desse modo, defende-se que estudos como os proporcionados por Feijoo e Magnan (2012, 2013) e Feijoo, Protasio e Magnan (2014) são importantes para o campo da Orientação Profissional. Essas pesquisas proporcionam problematizações e questionamentos que muitas vezes podem ser esquecidos ou que permanecem implícitos na sua práxis. Por outro lado, é por esse mesmo motivo que defendemos que a nomenclatura Análise da escolha profissional não deve ser vista como um novo nome para este campo, mas um outro discurso nele presente, isto é, um outro enfoque do campo da Orientação Profissional.

Uma autorreflexão parece ser necessária em relação ao que o presente artigo está discutindo. Adverte-se que não se está defendendo que se aceite tudo ou qualquer tipo de visão sem um exame detalhado e rigoroso. Pois, não se trata de um achismo: se tal pessoa ou tal abordagem acha determinado fato ou a interpretação de um fenômeno importante ou válido, isso não determina que eles, necessariamente, o serão. O que se põe em questão quando é dito que não há uma "verdade absoluta" é que não existe nenhum tipo de conhecimento que esteja para além de um contexto histórico e temporal. Defender o diálogo é defender uma conversa entre diferentes pontos de vistas e não tornar todos os pontos de vistas verdades absolutas; sempre há uma tensão no próprio ato do dialogar. Ou seja, abrir-se para o diálogo é também estar aberto para o questionamento e para a crítica do próprio discurso. Pensa-se que essa advertência é importante, pois, atualmente, a valorização de um individualismo que busca validar qualquer tipo de opinião é crescente - incluindo as opiniões que são repressoras e autoritárias e que são antidiálogo. Segundo Mori e Rouan (2018), naquilo que eles chamam de cultura pós-moderna, se vê surgir uma maior flexibilidade dos critérios da verdade e "a 
verdade absoluta cede seu lugar às verdades, umas mais diversas e mais 'verdadeiras' que as outras" (p. 17) e, por conseguinte, outras consideradas menos "verdadeiras". Escondendo que nesse discurso também há um jogo de tensão, disputa e poder. Há benefícios quando mais vozes são ouvidas e escutadas, isso é, poderíamos dizer, incontestável. Todavia, não se pode esquecer da responsabilidade atrelada ao falar.

Uma última indicação parece ser importante: a necessidade de repensar os fundamentos não só epistemológicos e metodológicos da Orientação Profissional, como também o repensar seus fundamentos ontológicos e filosóficos. O intuito seria o de pensar sobre aquilo que estabelece o próprio campo da Orientação Profissional e o seu papel — seja para a sociedade em que está inserida, seja para os grupos e sujeitos que passam pelo processo. Desse modo, pensa-se que a contribuição da Fenomenologia (junto com os outros agentes do campo da Orientação Profissional) pode ir além de um enfoque de Orientação. Beck (1977) realizou um estudo sistemático dos fundamentos filosóficos da Orientação, preocupando-se com o para além da prática. No capítulo quatro de sua obra - e que ele afirma ser a razão de ser de seu estudo (p. 6) - ele se utiliza da Dasainsanalyse, da Fenomenologia e do Existencialismo para uma "futura filosofia da orientação". Revisar e um repensar esses fundamentos deve ser constante. Quais novas questões surgiram desde a publicação de Beck e que devem ser consideradas num estudo sobre os fundamentos filosóficos de tal prática? Como deve-se entender a liberdade, o conhecimento, a sociedade, a escolha e a decisão, aquele que escolhe, e etc.? A serviço de quem está a Orientação profissional? Não tivemos a pretensão de responder essas questões31 no presente artigo, pois não são empreitadas do escopo deste trabalho. Entrementes, essas e outras questões parecem ser pertinentes para a Orientação Profissional e não para um ou outro enfoque específico, mas para o campo como um todo.

31 Não podemos esquecer que há pensadores nesse campo que fazem reflexões sobre questões similares. Um exemplo, para ilustrar, são as contribuições de Guichard e Huteau (2001). Eles propõem pensar o propósito da orientação e, em certa extensão, uma ética de sua prática. Outro exemplo é o de Ribeiro (2014) que articula, partindo de uma perspectiva socioconstrucionista, um novo estudo do fenômeno de carreiras a partir de um olhar psicossocial para entender a realidade enquanto um continuum ontológico relacional. 


\section{Considerações Finais}

Com o presente artigo pretendeu-se esboçar uma compreensão fundamentada na fenomenologia-hermenêutica para o termo orientação. $O$ orientar não é algo relacionado a uma prescrição externa e realizada por outrem; entrementes, está conectada com a própria pessoa que passa pelo processo. Configurando-se, desse modo, como um se orientar. Chegou-se à conclusão que tal nomenclatura pode ter espaço para se pensar o fenômeno da escolha profissional a partir de uma perspectiva fenomenológica-hermenêutica.

O se orientar, desse modo, se encontra em consonância com a definição de sentido exposto por Critelli (2007) como rumo, direção. A Orientação Profissional se apresenta como um espaço de cuidado para com a própria vida e futuro. Buscase propiciar ao orientando um convite para se apropriar do cuidado de sua (in)decisão.

Por mais que Feijoo e Magnan (2012, 2013) e Feijoo, Protasio e Magnan (2014), afirmam que o termo orientação deveria ser substituído por análise, pensase que essa manobra não é necessária. A questão não é o vocábulo em si, mas sim a maneira como se compreende o orientar. Como foi mostrado pelo artigo, a orientação não está necessariamente ligada a um direcionamento feito por outrem, mas está conectada em como a pessoa se orienta e se direciona na sua vida de uma maneira geral. Tal como na Análise da escolha profissional, não se afirma que o orientador deve ditar caminhos para serem percorridos pelo orientando, mas "como não há como o ser-aí não ser cuidado (Sorge) de si, seja de modo cuidadoso ou descuidado, o analista busca dar voz ao modo como cada analisando projeta o sentido de sua existência" (Feijoo, Protasio e Magnan, 2014, p. 72-73). O ponto central defendido é que a Orientação é um processo que convida o orientando para o cuidado de si. Um convite para pensar sobre o futuro, mas não impô-lo. Convite para a pessoa se apropriar da própria escolha, e (re)significar qual o sentido em que está orientada.

A questão e discussão da nomenclatura e nome do campo da Orientação Profissional, não só possibilitou repensar o significado do orientar e seu espaço nesse processo, mas também abriu um caminho para uma reflexão sobre o próprio 
campo. Com essas reflexões, levanta-se a proposição de que essa tensão do campo não é uma fraqueza, mas uma característica de sua identidade. Portanto, sugere-se que as diferentes abordagens se aproximem com o intuito de ensejar um debate, não necessariamente para se fundirem, mas de uma tal maneira que as permitam se fortalecerem pelo diálogo e questionamentos a partir das diferenças. Assim, de modo continuo se reconstituírem e se reinventarem de uma maneira rigorosa.

\section{Referências Bibliográficas}

ALMEIDA, M. E. G. G. DE. (Re)pensando a orientação vocacional na escola: da teoria à prática. Universidade de Aveiro, Aveiro, 2008.

BECK, C. E. Fundamentos filosóficos da orientação educacional. São Paulo, EPU, 1977. BERLIN, I. Two Concepts of Liberty: Original Dictation. Oxford: The Isaiah Berlin Virtual Library, $1958 . \quad$ Disponível em: <http://berlin.wolf.ox.ac.uk/published_works/tcl/tcl-e.pdf $>$.

BOHOSLAVSKY, R. Orientação Vocacional: a estratégia clínica. São Paulo: Martins Fontes, 2015.

BRUNS, M. A. de T. 1992. Não era bem isto o que eu esperava da universidade: um estudo de escolhas profissionais. Campinas. 217 f. Tese em Psicologia da Educação. Universidade Estadual de Campinas.

BUSA, A. L. A.; SILVA, G. B. DA; ROCHA, F. P. O Luto do Jovem Adulto Decorrente da Morte dos Pais pelo Câncer. Psicologia: Ciência e Profissão, v. 39, n. 2010, p. 1-13, 2019.

CLARK, K.; HOLQUIST, M. Mikhail Bakhtin. São Paulo: Perspectiva, 2008.

CRITELLI, D. M. Analítica do Sentido: uma aproximação a interpretação do real de oriente- tação fenomenológica. 2. ed. São Paulo: Brasiliense, 2007. 
CRITELLI, D. M. História pessoal e sentido da vida: historiobiografia. São Paulo: EDUC; FAPESP, 2016.

DELORY-MOMBERGER, C. Biographie, socialisation, formation. L'Orientation scolaire et professionnelle, n. 33/4, p. 551-570, 2004. Disponível em: $<$ http://journals.openedition.org/osp/251>.

DUARTE, A. Heidegger e a possibilidade de uma antropologia existencial. Natureza humana, v. 6, n. 1, p. 29-51, 2004.

FEIJOO, A. M. L. C. de; MAGNAN, V. D. C. Análise da Escolha Profissiomal: Uma Proposta Fenomenológica-Existencial. Psicologia: Ciência e Profissão, v. 32, n. 2, 2012. FEIJOO, A. M. L. C. de; MAGNAN, V. D. C. Análise da Escolha Profissional. Rio de Janeiro: Edições IFEN, 2013.

FEIJOO, A. M. L. C. de; PROTASIO, M. M.; MAGNAN, V. D. C. Análise da escolha profissional: orientação ou libertação? Ekstasis: Revista de Hermenêutica $e$ Fenomenologia, v. 3, n. 2, p. 57-73, 2014. Disponível em: <http://www.epublicacoes.uerj.br/index.php/Ekstasis/article/view/14076>.

FREITAS, D. P. de. Daseinsanalyse e liberdade. Daseinsanalyse, v. 15-16, 2011.

GUICHARD, J. Se faire soi. L'Orientation scolaire et professionnelle, n. 33/4, p. 499533, 2004.

GUICHARD, J.; HUTEAU, M. Psychologie de l'orientation. Paris: Dunod, 2001.

GUIGNON, C. B. Authenticity, moral values, and psychotherapy. In: C. B. Guignon (Org.); The Cambridge Companion to Heidegger. Cambridge: Cambridge University Press, 1993.

HEIDEGGER, M. Introdução à filosofia. 2a ed. São Paulo: WMF Martins Fontes, 2009. HEIDEGGER, M. Ser e Tempo. Campinas; Petrópolis: Editora da Unicamp; Vozes, 2012. KAÜFER, S.; CHEMERO, A. Phenomenology: an introduction. Cambridge; Malden: Polity Press, 2015.

MORI, S.; ROUAN, G. As terapias narrativas. São Paulo: Edições Loyola, 2018.

MUCHAIL, S. T. Foucault, simplesmente: textos reunidos. São Paulo: Edições Loyola, 2004. 
PELlETIER, D., BUJOLD, C., \& NOISEUX, G. Desenvolvimento Vocacional $e$ Crescimento Pessoal. São Paulo: Vozes, 1979.

PIMENTA, S. G. 1979. A decisão em orientação vocacional: caracterização do significado da orientação vocacional na educação brasileira, através da crítica aos enfoques da psicologia e da fenomenologia existencial. São Paulo. Dissertação em Filosofia da Educação. Pontifícia Universidade Católica de São Paulo.

POMPÉIA, J. A. Psicoterapia e verdade. Daseinsanalyse, v. 4, 1978.

REIS, R. R. "Sentido e Verdade: Heidegger e 'A Noite Absoluta'”. Veritas, v. 45, no 2, Porto Alegre, 2000

REIS, R. R. DOS. Aspectos da Modalidade: A Noção de Possibilidade na Fenomenologia Hermenêutica. Rio de Janeiro: Via Verita, 2014.

RIBEIRO, M. A. Sexta demanda-chave para a Orientação Profissional: como ajudar o indivíduo a construir dinamicamente sua carreira em um mundo em transição? In: M. A. Ribeiro; L. Melo-Silva (Orgs.); Compêndio de orientação profissional e de Carreira, volume 2. São Paulo: Vetor, 2011.

RIBEIRO, M. A. Breve histórico dos primórdios da Orientação Profissional. In: M. A. Ribeiro; L. Melo-Silva (Orgs.); Compêndio de orientação profissional e de Carreira, volume 1. São Paulo: Vetor, 2011a.

RIBEIRO, M. A.; LEHMAN, Y. P. Algumas contribuições brasileiras para a Orientação Profissional. In: M. A. Ribeiro; L. Melo-Silva (Orgs.); Compêndio de orientação profissional e de Carreira, volume 2. São Paulo: Vetor, 2011.

RIBEIRO, M. A. Carreiras: novo olhar socioconstrucionista para um mundo flexibilizado. Curitiba: Juruá, 2014.

RIBEIRO, M. A.; MELO-SILVA, L. Compêndio de orientação profissional e de carreira, volume 1. São Paulo: Vetor, 2011a.

RIBEIRO, M. A.; MELO-SILVA, L. Compêndio de orientação profissional e de carreira, volume 2. São Paulo: Vetor, 2011b.

RIBEIRO, M. A.; UVALDO, M. DA C. C. Primeira demanda-chave para a Orientação Profissional: como ajudar o indivíduo a realizar o seu ajustamento vocacional/profissional? Enfoque traço-fator. In: M. A. Ribeiro; L. Melo-Silva (Orgs.); Compêndio de orientação profissional e de Carreira, volume 1. São Paulo: Vetor, 2011. 
SAPIENZA, B. T. Do desabrigo a confiança: Daseinsanalyse e terapia. São Paulo: Escuta, 2013.

TEIXEIRA, M. O. Quarta demanda-chave para a Orientação Profissional: Como ajudar o indivíduo a compreender seu processo de tomada de decisões e desenvolver um método de escolha: Enfoque decisional e cognitivo. In: M. A. Ribeiro; L. Melo-Silva (Orgs.); Compêndio de orientação profissional e de Carreira, volume 1. São Paulo: Vetor, 2011. VALACH, L., \& YOUNG, R. A. "Contextual Action Theory in Career Counselling: some misunderstood issues". Canadian Journal of Counselling and Psychotherapy, v. 36, $n^{\circ} 2,2002$

WRATHALL, M. A. “Unconcealment”. In.: DREYFUS, H. L. e WRATHALL, M. A (orgs.) A companion to Heidegger. Boston: Blackwell, 2005.

Recebido em: 01/02/2020 | Aprovado em: 04/05/2020 